Journal of ASTM International October 2009, Vol. X, No. X

Paper ID

Available online at www.astm.org

Keisa R. Rosales ${ }^{1}$ and Joel M. Stoltzfus ${ }^{2}$

\title{
High Pressure Quick Disconnect Particle Impact
}

\section{Tests}

\begin{abstract}
NASA Johnson Space Center White Sands Test Facility (WSTF) performed particle impact testing to determine whether there is a particle impact ignition hazard in the quick disconnects (QDs) in the Environmental Control and Life Support System (ECLSS) on the International Space Station (ISS). Testing included standard supersonic and subsonic particle impact tests on 15-5 PH stainless steel, as well as tests performed on a QD simulator.
\end{abstract}

This paper summarizes the particle impact tests completed at WSTF. Although there was an ignition in Test Series 4, it was determined the ignition was caused by the presence of a machining imperfection. The sum of all the test results indicates that there is no particle impact ignition hazard in the ISS ECLSS QDs.

KEYWORDS: quick disconnect, high pressure, particle impact testing, stainless steel

\footnotetext{
${ }^{1}$ Chemical Engineer, NASA Test and Evaluation Contract, P.O. Box 20, Las Cruces, New Mexico 88004.

${ }^{2}$ Project Manager, NASA White Sands Test Facility, P.O. Box 20, Las Cruces, New Mexico 88004.
} 


\section{List of Notations}

\begin{tabular}{ll}
\hline \multicolumn{2}{l}{ Abbreviations } \\
\hline ECLSS & Environmental Control and Life Support System \\
ISS & International Space Station \\
QD & Quick disconnect \\
SS & Stainless steel \\
WSTF & NASA White Sands Test Facility \\
\hline
\end{tabular}

\section{Introduction}

Gas velocities inside the quick disconnects (QDs) in the Environmental Control and Life Support System (ECLSS) on the International Space Station (ISS) are great enough to raise concerns about a possible particle impact ignition hazard. These high velocities will occur any time the QDs are mated under pressure, when the airlock tanks are used to repressurize the system, and when the recharge oxygen orifice bypass assembly is used to bypass a flow-limiting orifice during pressurization of the airlock tanks. As a result of concerns that the high gas velocities could cause ignition due to particle impact in the QDs, NASA Johnson Space Center requested White Sands Test Facility (WSTF) to perform testing to determine whether there is a particle impact ignition hazard in the QDs.

Testing included standard supersonic and subsonic particle impact tests on 15-5 PH stainless steel (SS), as well as tests performed on a QD simulator. The particulate mixture used was consistent with the system materials of construction. This paper summarizes the testing completed at WSTF.

\section{Objective}

The test objective was to determine if particle impact samples and a QD simulator composed of 15-5 PH SS would ignite and burn when impacted by particulate, and to determine the effect of the impact at the given temperatures, pressures, and flow rates. 


\section{Test Methods}

The selection of test materials, the test series, and the test procedures are described.

\section{Materials}

The following paragraphs discuss the particulate mixtures, the test target and QD simulator materials, and the sample preparation.

Particulate Mixtures - Two particulate mixtures were used, as described in Table 1 and shown in Figures 1 and 2. The materials that made up the particulate mixtures (stainless steels, Inconel ${ }^{\circledR 3}$ alloys, and Monel $^{\circledR 4}$ alloys) are native to the ISS ECLSS. The ISS ECLSS was initially cleaned to Level 200, which dictates no particles greater than $200 \mu \mathrm{m}$ and a maximum allowed distribution for particles smaller than $200 \mu \mathrm{m}$. Small amounts of assembly and operationally generated particulates could be present in the system.

In previous particle impact tests on the Space Shuttle flow control valve [1], calculations were performed to determine the amounts of particulate allowed in the propulsion system, external tank, and main engine, based on the surface areas in those systems. The calculated amount of allowed particulate was then multiplied by a safety factor, and the resulting amount used for testing was $10 \mathrm{mg}$. Similar calculations have not been performed for the ISS ECLSS system; however, the surface area of the ECLSS system is much smaller. Therefore, the materials and quantities of particulates used in Mixtures A and B are considered to be extremely conservative because the amount of particles is on the same order as those used for the flow control valve tests. In addition, the size range of the particles encompasses those that would be allowed in the system by the cleanliness level, as well as larger particles.

Test Target and Quick-Disconnect Simulator Materials - The standard supersonic and subsonic configurations used 15-5 PH SS targets, corresponding to the material used at the impingement points

\footnotetext{
3 Inconel $^{\circledR}$ and Monel ${ }^{\circledR}$ are registered trademarks of Inco Alloys International, Inc., Huntington, West Virginia
} 
inside the ISS ECLSS QDs. For the supersonic tests, these targets were configured in a cup shape with an outside diameter ( 0.375 in.) that allowed flow over and around the target surface. Each supersonic target sample was press-fitted onto a copper sample holder, as shown in Figure 3. The standard subsonic configuration targets were 0.060 -in.-thick flat discs with holes drilled radially to allow flow over and through the target (Figure 4).

The QD simulator tests were performed using WSTF-machined parts composed of 15-5 PH SS. The design of the QD simulator parts replicated the relevant parts inside the flight QDs, based on information supplied by the manufacturer. Figure 5 shows a cross section of the QD simulator used for testing.

Sample Preparation-All samples were prepared at WSTF and cleaned in a mild detergent. The samples were then sealed in polypropylene bags until testing. From this point, the targets and simulator parts were handled with latex gloves to maintain cleanliness.

\section{Test Series and Procedures}

All tests were performed in the WSTF High Flow Test Facility. During particle impact testing, the parameters of concern are temperature, pressure, particle composition, target, and configuration. The maximum pressure in the ISS ECLSS QDs is $3000 \mathrm{psi}$, and the maximum temperature is $115^{\circ} \mathrm{F}$. The test temperature for all tests was $115^{\circ} \mathrm{F}$. Six test series were performed, as described in Table 2 .

For Test Series 1 and 2, the supersonic nozzle was installed on the outlet of the subsonic injector assembly. The particulate was loaded into the injector, and the injector cap was threaded onto the housing. The target sample and copper posts were then positioned at the end of the nozzle (Figure 6). An untested sample was used for each test.

For Test Series 3, the subsonic injector and nozzle were used. The particulate was loaded into the injector, and the injector cap was then threaded onto the housing. The target sample and orifice (for controlling the gas velocity) were then positioned on the end of the subsonic nozzle (Figure 7). An untested sample was used for each test. 
For Test Series 4, 5, and 6, the QD simulator was installed on the outlet of the flow straightener and subsonic particle injector assembly (Figure 8). The particulate was loaded into the injector, and the injector cap was then threaded onto the housing. The same QD simulator was used for all tests.

For all test series, after system preparation was completed the test area was cleared of personnel and placed in RED (no access allowed) status. A video camera was positioned to record any reaction visible at the end of the test fixture. Heated gaseous aviator's breathing oxygen (ABO) at test pressure was allowed to flow until the temperature of the target sample was achieved and the gas flow stabilized. Upon command, the particulate was injected into the chamber. After evidence of impact, the oxygen flow was terminated and the test system was allowed to vent down to ambient pressure, $\sim 4 \mathrm{~s}$ after particle injection. After every test in Test Series 1, 2, and 3, each target sample was visually inspected to verify that particle impacts had occurred. Each sample was then individually bagged in its original bag and labeled with test information. The test computer saved the test and system data. The test pressure, test temperature, and average flow meter reading were recorded in the test area log book. Videotapes of the test were recorded and stored. At the completion of these tasks, the procedure was repeated.

\section{Results and Discussion}

The effect of impact on the test sample at the given temperatures, pressures, and flow rate was determined visually and characterized in accordance with NASA-STD-6001 [2], as follows:

- For testing materials

No Ignition - characterized by no evidence of combustion. A material that does not ignite may show one or more particle indentations on the surface of the material, which may include localized erosion Ignition - a portion or the entire sample is consumed; the target may not be recoverable.

- For testing components 
No Ignition - characterized by no evidence of combustion. A component that does not ignite may show one or more particle indentations on the inside surface of the component, which may include localized erosion Ignition - characterized by obvious consumption of the component, which may include burnout.

For a summary of all the test results, see Table 2.

\section{Test Series 1}

In Test Series 1, 100 tests were performed in ABO-grade oxygen with a target pressure of $1050 \mathrm{psi}$ and a target temperature of $115^{\circ} \mathrm{F}$. There were no ignitions of the test samples in 100 tests. The test pressure for Test Series 1 was chosen to simulate the environment in the low pressure ECLSS QDs. It was not yet known that there would be particle impact concerns in the high pressure ECLSS QDs, which have a maximum pressure of 3000 psi (see Test Series 4). Figure 9 shows a typical posttest test sample.

\section{Test Series 2}

In Test Series 2, 85 tests were performed in ABO-grade oxygen with a target pressure of $1700 \mathrm{psi}$ and a target temperature of $115^{\circ} \mathrm{F}$. There were no ignitions of the test samples in 85 tests. Although higher test pressures were desired to simulate the maximum pressure in the high pressure ECLSS QDs, 1700 psi was the maximum capability of WSTF's supersonic particle impact test system due to the large pressure drop through the supersonic nozzle. Figure 10 shows a typical posttest sample.

\section{Test Series 3}

In Test Series 3, 60 tests were performed in ABO-grade oxygen with a system pressure of $3000 \mathrm{psi}$ and system gas temperature of $115^{\circ} \mathrm{F}$. Unlike the supersonic tests, these subsonic tests 
measured the pressure and temperature upstream of the test sample. There were no ignitions of the test samples in 60 tests. The orifice size was $0.344 \mathrm{in}$, which led to an average gas velocity of $425 \mathrm{ft} / \mathrm{s}$ (calculated from results obtained by the system mass flow meter). This test series was performed because greater test pressures could not be obtained in Test Series 2. Figure 11 shows a typical posttest sample.

\section{Test Series 4}

In Test Series 4, one test was performed in $\mathrm{ABO}$-grade oxygen with a pressure at the inlet of the QD simulator of $3000 \mathrm{psi}$ and system gas temperature of $115^{\circ} \mathrm{F}$. There was an ignition of the QD simulator on the first test. The flow direction in the QD simulator was from the female side to the male side. Figure 12 shows the burned QD simulator. Following the ignition, the QD simulator was sectioned to inspect the internal parts and burned area. Upon inspection, a machining imperfection was found at the inlet of the throat (Figure 13). It was believed that the machining imperfection caused the velocities to increase and the flow to become turbulent prior to reaching the replicated QD parts. The velocity

made the test unnecessarily severe and unrealistic since the inspected flight QDs would not have similar imperfections. Therefore, a new QD simulator was machined for the subsequent test series.

\section{Test Series 5}

A new QD simulator, verified to have no machining imperfections, was used in Test Series 5. 60 tests were performed in $100 \%$ oxygen with a pressure of $2500 \mathrm{psi}$ at the inlet of the QD simulator and a test gas temperature of $115^{\circ} \mathrm{F}$. Test Series 5 was the only series which used particulate Mixture B. Because the ignition in Test Series 4 raised many concerns about upcoming ISS ECLSS operations, the test pressure was chosen to envelop the worst-case pressure in near-term operations and the particulate mixture was made less severe, as Mixture A was considered to be overly conservative. There were no ignitions of the QD simulator in 60 tests. Posttest inspections revealed that the larger particulates were 
getting caught in various locations inside the QD simulator, as shown in Figures 14, 15, and 16. Therefore, after each test was performed, the QD simulator had to be disassembled, cleaned, and reassembled.

\section{Test Series 6}

In Test Series 6, tests were performed to repeat the same test conditions where the ignition occurred in Test Series 4, but without the machining imperfection. Sixty tests were performed in $100 \%$ oxygen with a pressure of $3000 \mathrm{psi}$ at the inlet of the QD simulator and a test gas temperature of $115^{\circ} \mathrm{F}$. There were no ignitions of the QD simulator in 60 tests. Just as in Test Series 5, posttest inspections revealed that the larger particulates were getting caught inside the QD simulator in various locations, as shown in Figures 14, 15, and 16. The results of Test Series 6 indicate that the machining imperfection found in Test Series 4 was the cause of the ignition.

\section{Conclusions}

Six series of tests were performed on 15-5 PH SS targets and a QD simulator at subsonic and supersonic velocities to determine if a particle impact ignition hazard existed in the QDs. In the 366 tests with a variety of particle mixes, no ignition and sustained burning of the aluminum occurred except one in Test Series 4. The results of Test Series 6 indicate that the ignition in Test Series 4 was caused by the presence of the machining imperfection. The sum of all the test results indicates that there is no particle impact ignition hazard in the ISS ECLSS QDs.

\section{References}

[1] Benz, F. J., R. E. Williams, and D. Armstrong, "Ignition of Metals and Alloys by High-Velocity Particles," Flammability of Materials in Oxygen-Enriched Atmospheres, Vol. 2 STP 910, M. A. 
Benning, Ed., American Society for Testing of Materials, West Conshohocken, Pennsylvania, January 1986.

[2] NASA. Flammability, Odor, Offgassing, and Compatibility Requirements and Test Procedures for Materials in Environments that Support Combustion, NASA-STD-6001 Test 15, Marshall Space Flight Center, Alabama, February 9, 1998. 
TABLE 1-Particulate mixtures used for testing.

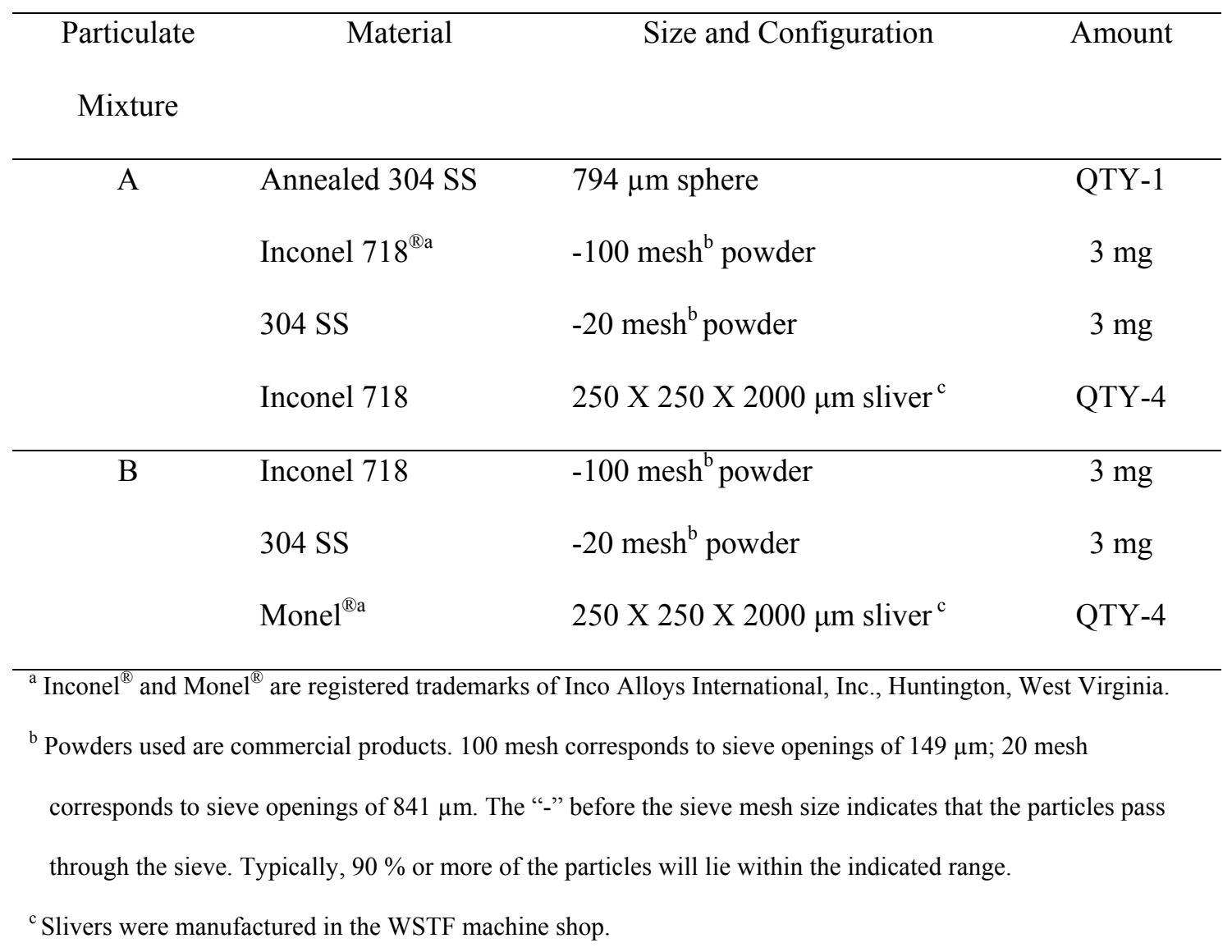


TABLE 2-Particle impact test series and results summary.

\begin{tabular}{|c|c|c|c|c|c|c|}
\hline Test & Test System & Particulate & Test & Test & Number & Number \\
\hline Series & Configuration & Mixture $^{a}$ & $\begin{array}{l}\text { Pressure } \\
\text { (psig) }\end{array}$ & $\begin{array}{c}\text { Temperature } \\
\left({ }^{\circ} \mathrm{F}\right)\end{array}$ & of Tests & $\begin{array}{c}\text { of } \\
\text { Ignitions }\end{array}$ \\
\hline 1 & $\begin{array}{l}\text { Subsonic injector with } \\
\text { supersonic nozzle }\end{array}$ & A & 1050 & 115 & 100 & 0 \\
\hline 2 & $\begin{array}{l}\text { Subsonic injector with } \\
\text { supersonic nozzle }\end{array}$ & A & 1700 & 115 & 85 & 0 \\
\hline 3 & $\begin{array}{l}\text { Subsonic injector with } \\
\text { subsonic nozzle }\end{array}$ & A & 3000 & 115 & 60 & 0 \\
\hline 4 & QD simulator & A & 3000 & 115 & 1 & 1 \\
\hline 5 & QD simulator & B & 2500 & 115 & 60 & 0 \\
\hline 6 & QD simulator & A & 3000 & 115 & 60 & 0 \\
\hline
\end{tabular}

\footnotetext{
${ }^{\mathrm{a}}$ Particulate mixtures are described in Table 1 of this report.
} 


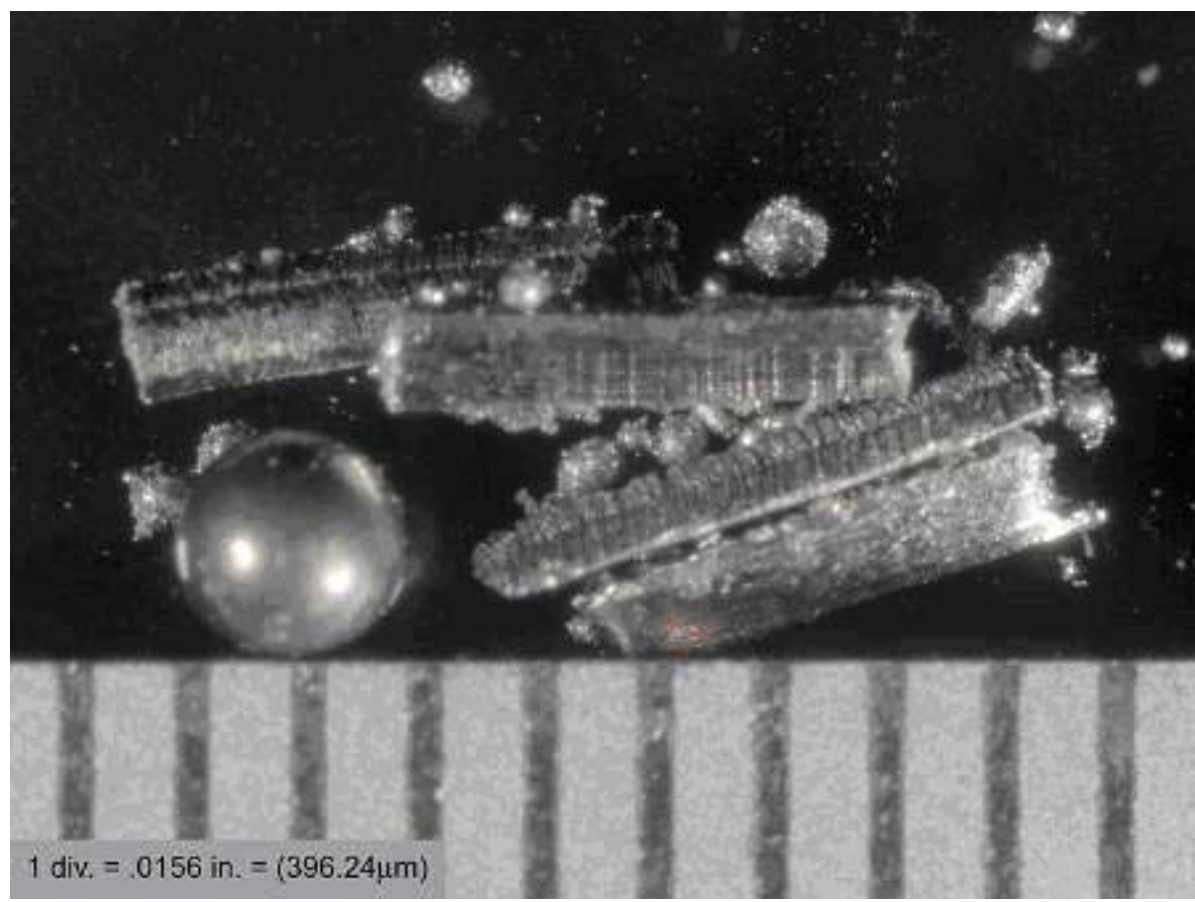

wstf1206e08470

FIG. 1-Particulate mixture A. 


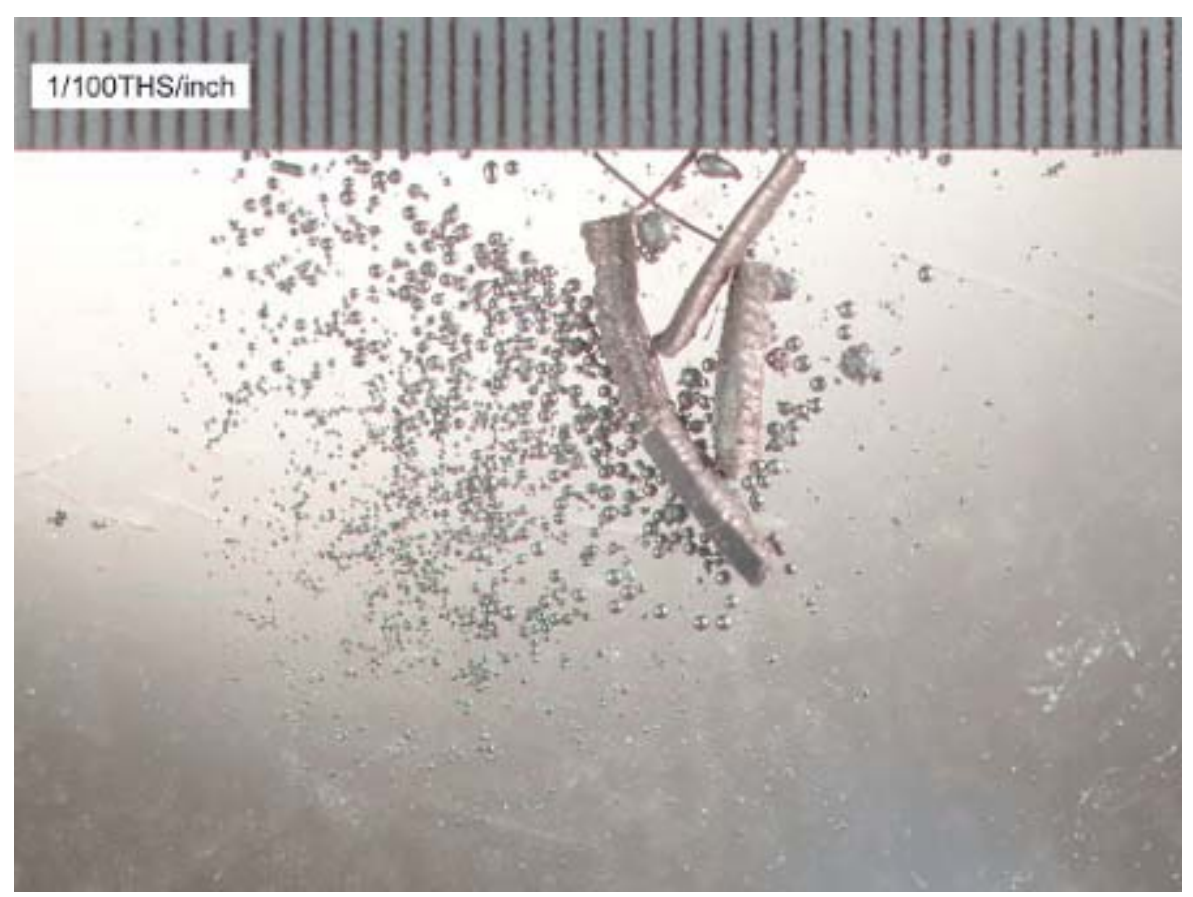

wstf0607e04134

FIG. 2-Particulate mixture B. 
14 JOURNAL OF ASTM INTERNATIONAL

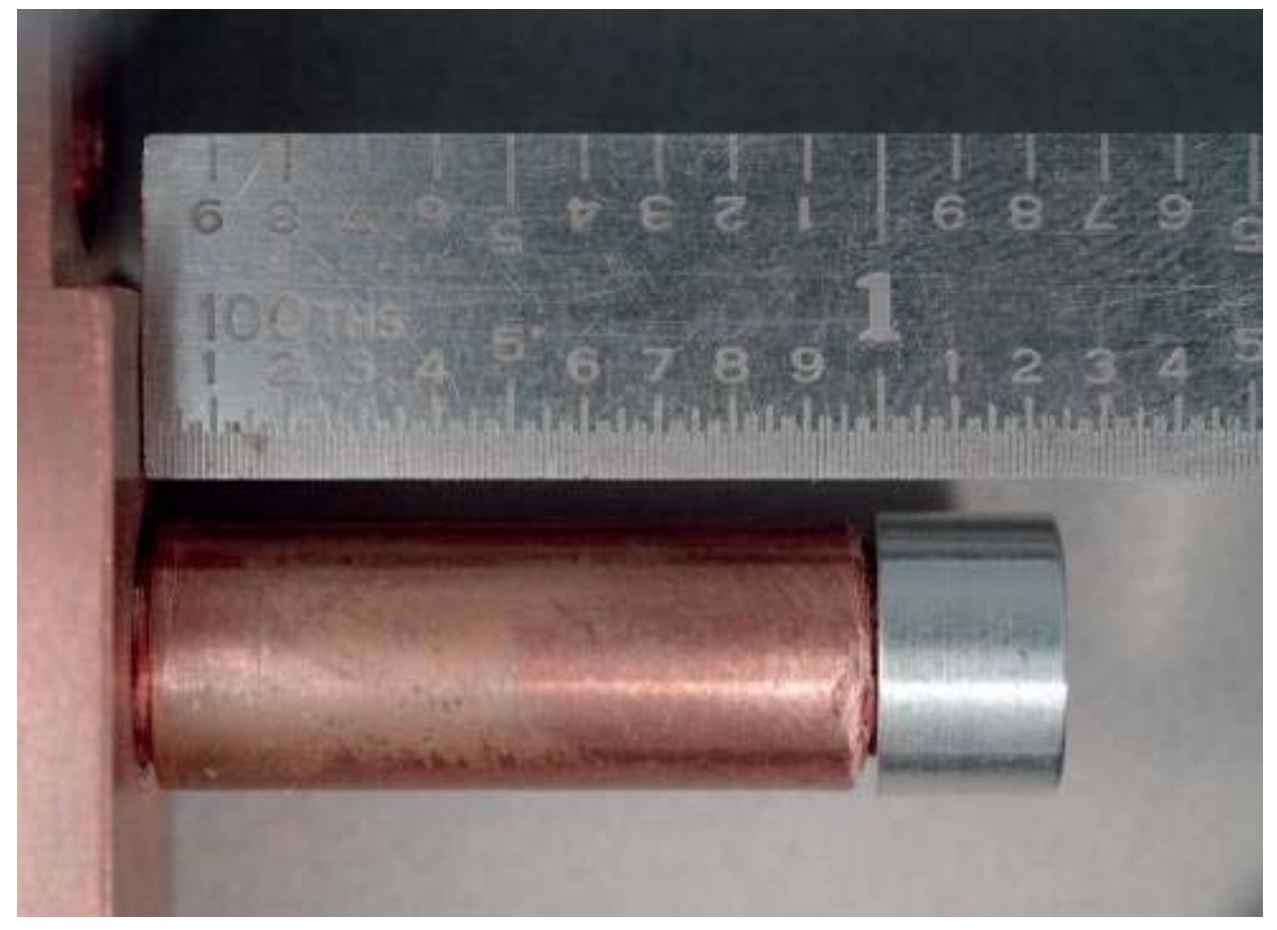

wstf0806e05396

FIG. 3-Standard supersonic target configuration. 


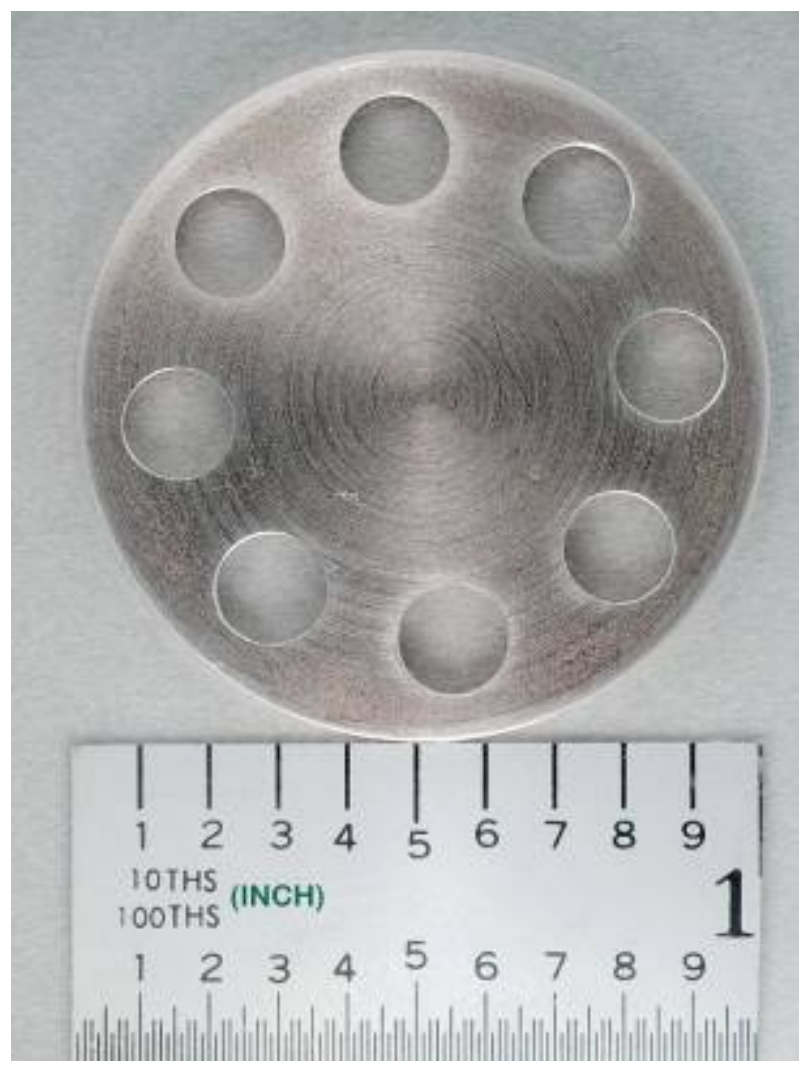

wstf0406e01981

FIG. 4-Standard subsonic flat target configuration. 


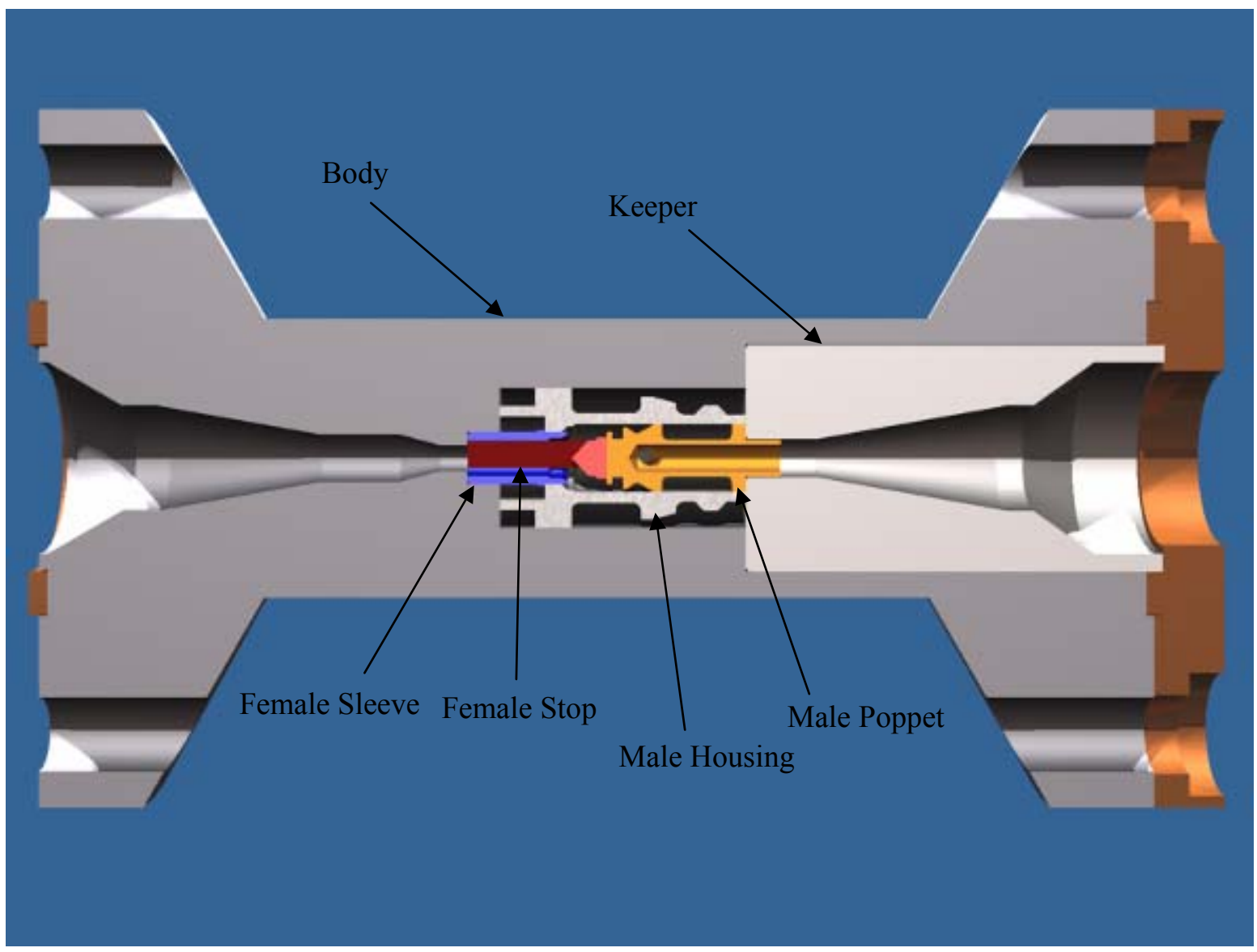

FIG. 5-Cross section of QD simulator. 


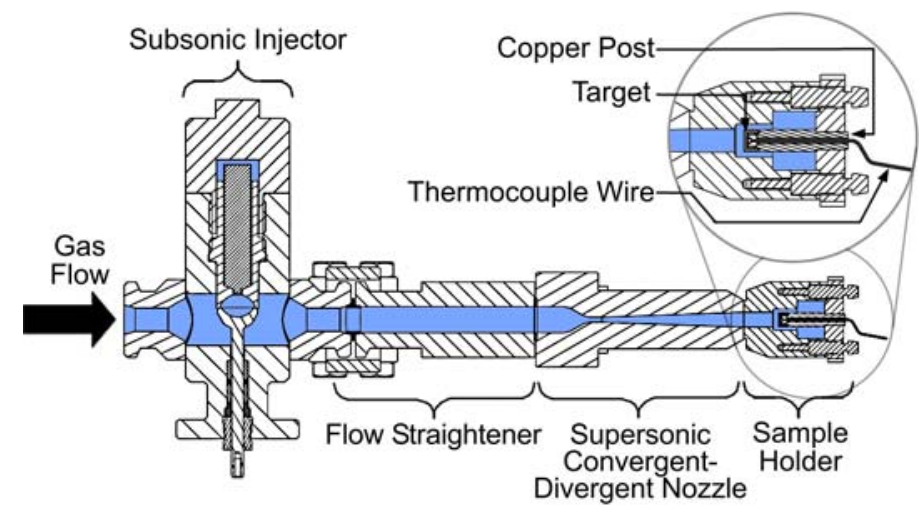

FIG. 6-Subsonic injector with supersonic nozzle used for Test Series 1 and 2.

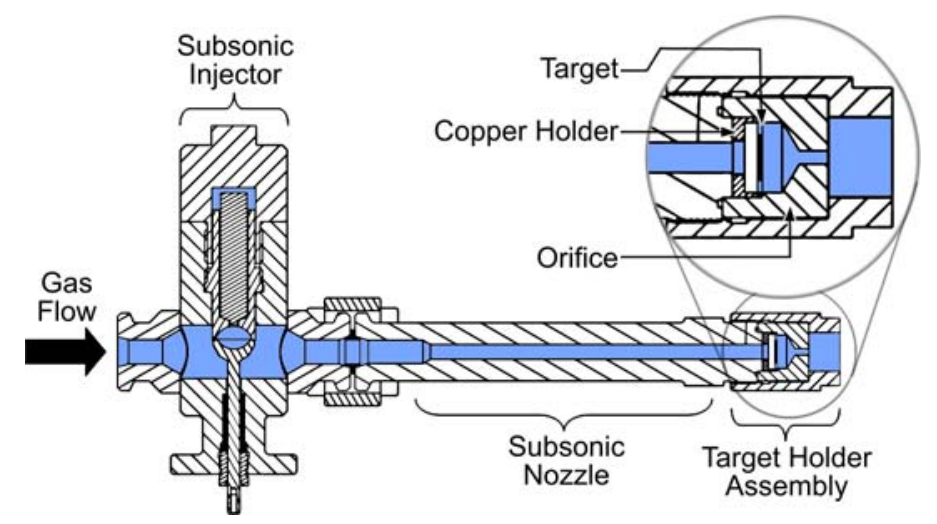

FIG. 7—Subsonic injector and nozzle used for Test Series 3. 
18 JOURNAL OF ASTM INTERNATIONAL

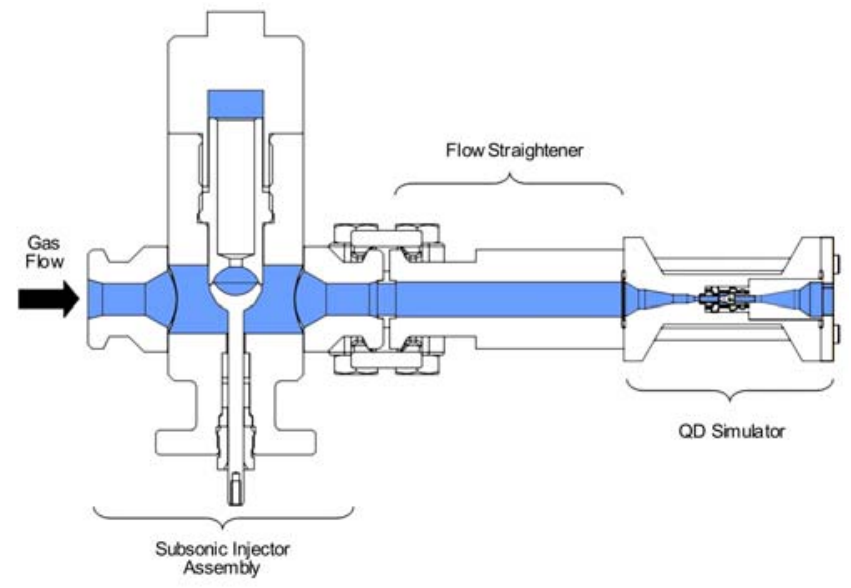

FIG. 8-QD simulator test system used for Test Series 4, 5, and 6. 


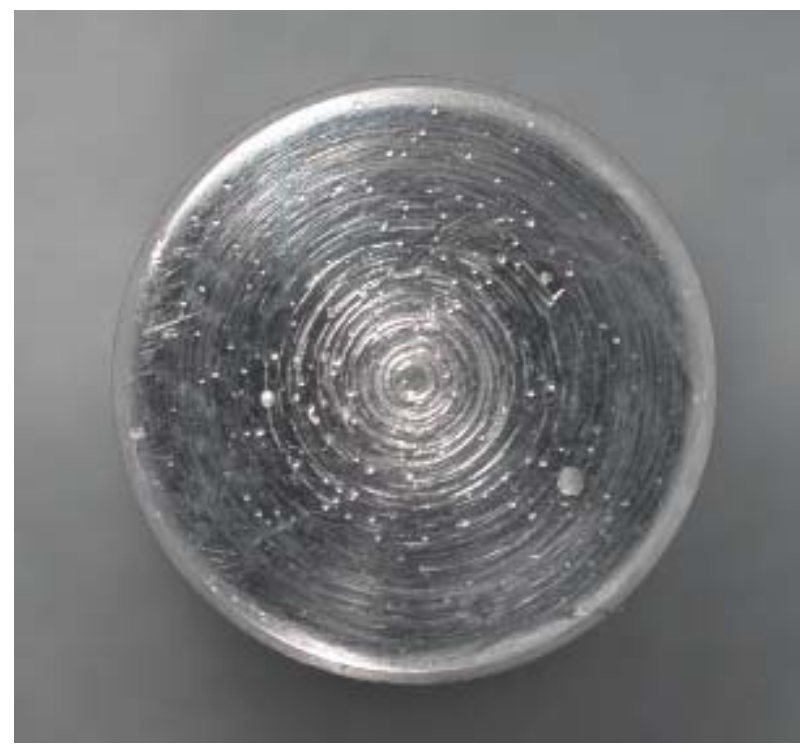

wstf0607e04624

FIG. 9-Typical Test Series 1 supersonic posttest sample at 1050 psi. 


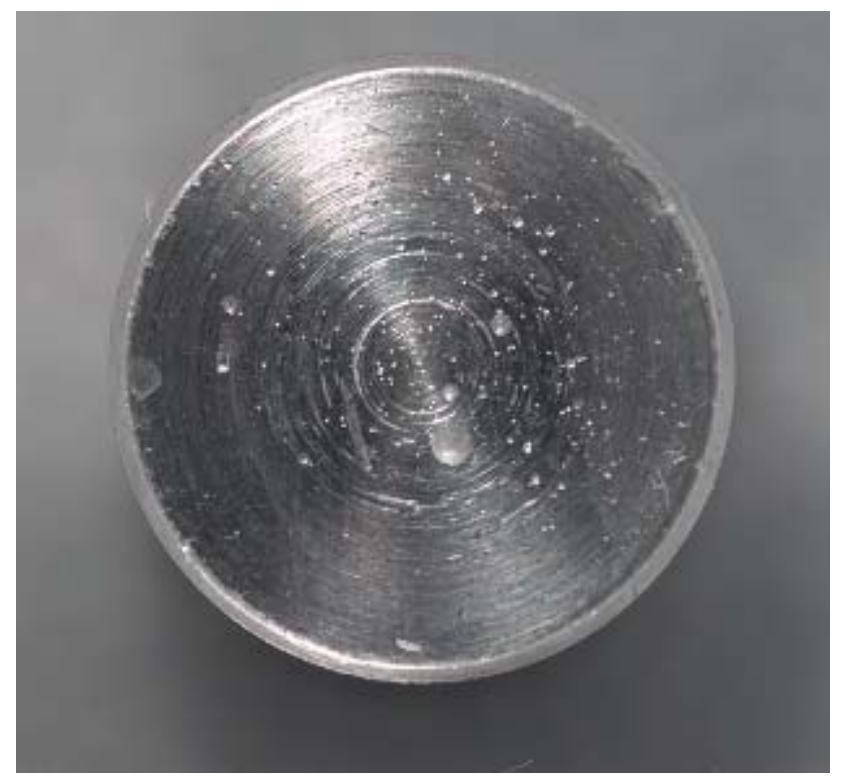

wstf0607e04626

FIG. 10-Typical Test Series 2 supersonic posttest sample at 1700 psi. 


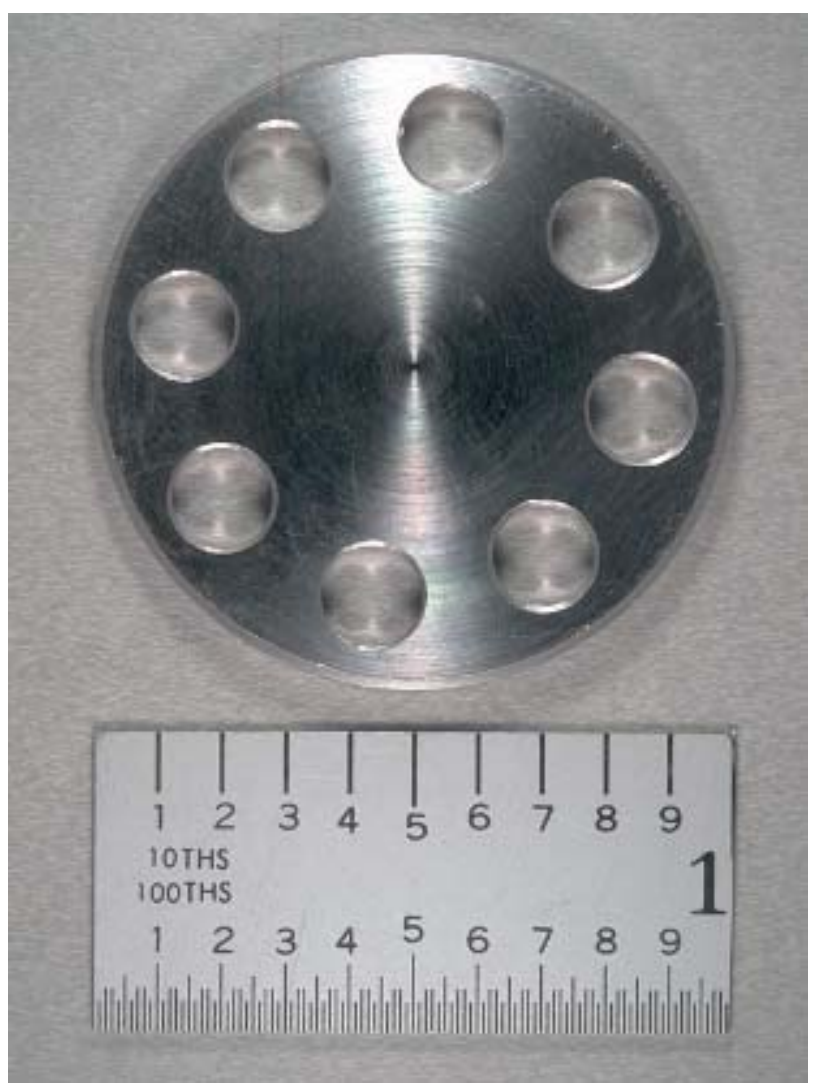

wstf0607e04628

FIG. 11-Typical Test Series 3 subsonic posttest sample at 3000 psi. 
22 JOURNAL OF ASTM INTERNATIONAL

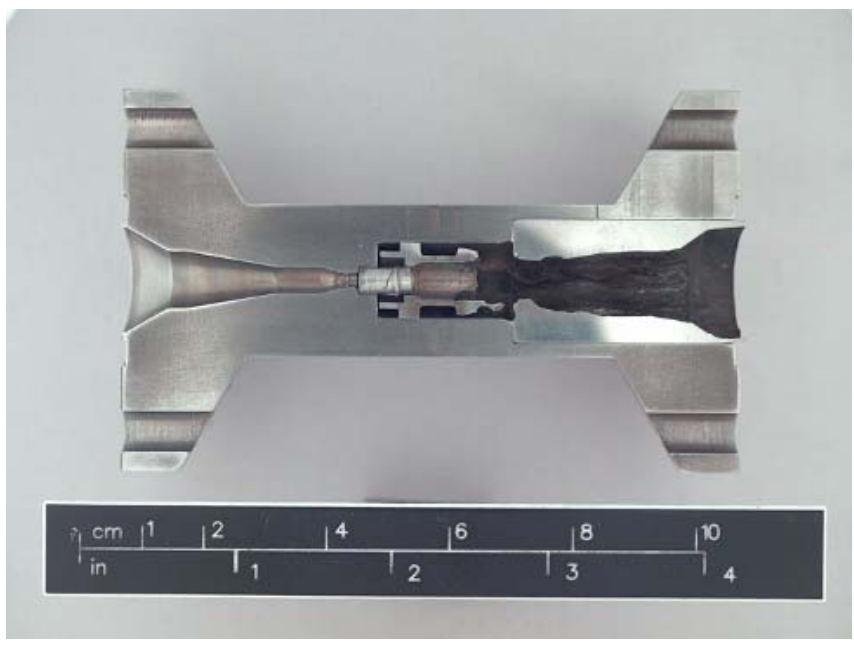

wstf0607e04621

FIG. 12-Burned QD simulator. 


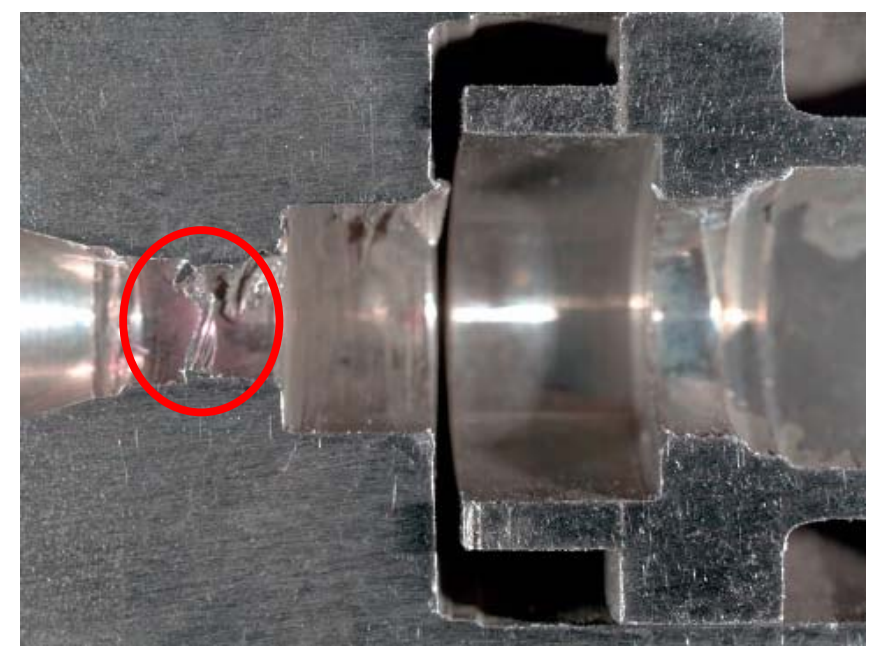

wstf0607e04623

FIG. 13-Location of machining imperfection. 
24 JOURNAL OF ASTM INTERNATIONAL

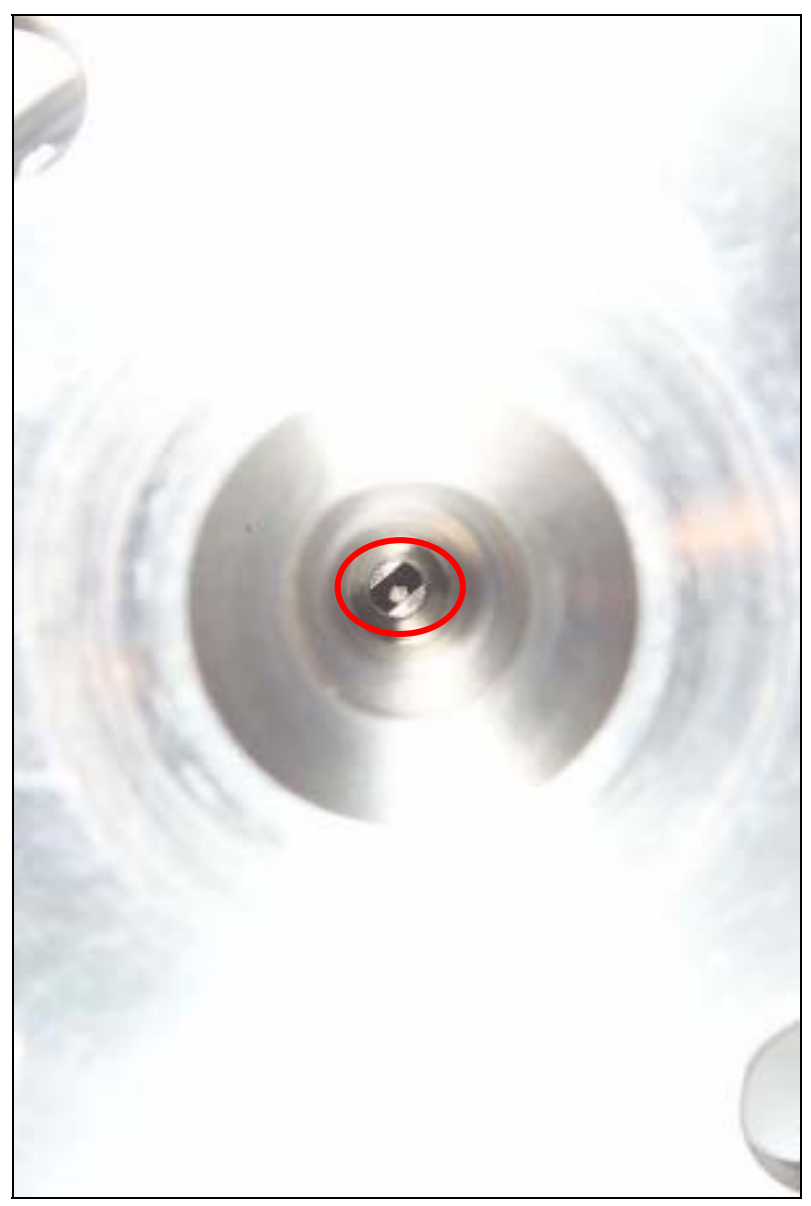

wstf0507e03897

FIG. 14-Particulate caught in inlet of female stop. 


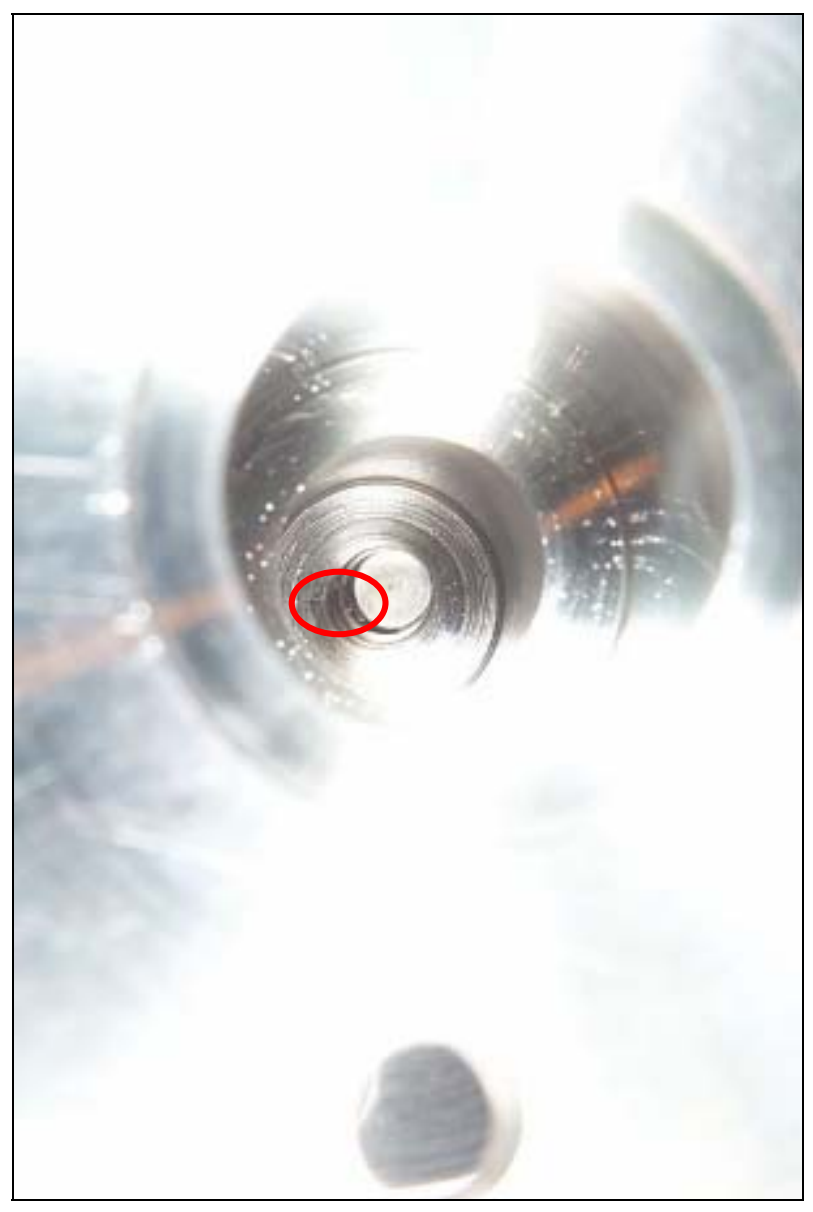

wstf0507e03898

FIG. 15-Particulate caught in outlet of female stop. 


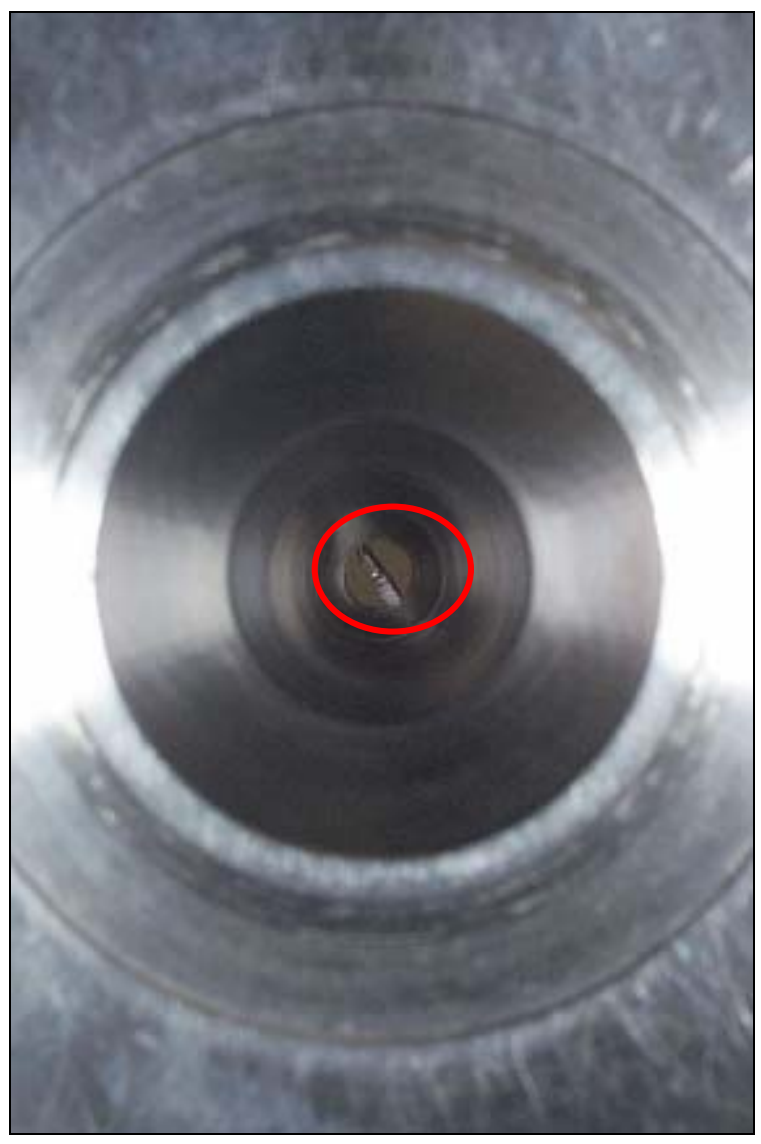

wstf0507e03901

FIG. 16-Particulate caught in the inlet of the QD. 